\title{
Tracheostomy in children with congenital heart disease: a national analysis of the Kids' Inpatient Database.
}

Background: While single-institution studies reported the indications and outcomes of tracheostomy in children with congenital heart disease (CHD), no national analyses have been performed. We sought to examine the indications, performance, outcomes, and resource utilization of tracheostomy in children with CHD using a nationally representative database.

Methods: We identified all children undergoing tracheostomy in the Kids' Inpatient Database 1997 through 2009, and we compared children with CHD to children without CHD. Within the CHD group, we compared children whose tracheostomy occurred in the same hospital admissions as a cardiac operation to those whose tracheostomy occurred without a cardiac operation in the same admission.

Results: Tracheostomy was performed in $n=2,495$ children with $C H D$, which represents $9.6 \%$ of all tracheostomies performed in children $(n=25,928)$, and $3.5 \%$ of all admissions for children with CHD $(n=355,460)$. Over the study period, there was an increasing trend in the proportion of all tracheostomies that were done in children with $\mathrm{CHD}(\mathrm{p}<0.0001)$ and an increasing trend in the proportion of admissions for children with CHD that involved a tracheostomy $(p<0.0001)$. The population of children with CHD undergoing tracheostomy differed markedly in baseline characteristics, outcomes, and resource utilization. Similarly, the subgroup of children whose tracheostomy was performed in the same admission as a cardiac operation differed significantly from those whose tracheostomy was not. 
Conclusions: Tracheostomy is an increasingly common procedure in children with CHD despite being associated with significantly greater resource utilization and in-hospital mortality. The population of children with CHD who undergo tracheostomy differs markedly from that of children without CHD who undergo tracheostomy, and important differences are observed between children who undergo tracheostomy in the same admission as a cardiac surgical procedure and those who undergo tracheostomy in a nonsurgical admission, as well as between children with single-ventricle physiology and children with two-ventricle physiology. 
2 Bryan G. Maxwell, MD, MPH

3 Kristen Nelson McMillan, MD

4 From the Department of Anesthesiology and Critical Care Medicine, Johns Hopkins University

5 School of Medicine, Baltimore, MD. 


\section{Introduction}

7 Congenital heart disease (CHD) has become more prevalent worldwide.(van der Linde et

8 al., 2011) Surgical techniques to treat even the most complex structural lesions, along with

9 improved intensive care unit (ICU) capabilities, have improved survival for children with CHD.

10 (Nieminen, Jokinen \& Sairanen, 2001) But with greater long-term survival of children with

11 complex CHD and other significant comorbid conditions, a fraction of children with CHD require

12 tracheostomy for airway protection and/or ventilator dependence. Many children experience a

13 prolonged and difficult recovery after cardiac operations, and even after the initial recovery,

14 children with CHD have greater vulnerability to subsequent critical illness.(Székely et al., 2006)

15 For instance, even routine respiratory infections can be life-threatening and require ventilator

16 support in children with complex, palliated CHD.

17 Single-institution studies(Challapudi, Natarajan \& Aggarwal; LoTempio \& Shapiro;

18 Hoskote et al., 2005; Rossi et al., 2009; Cotts et al., 2011; Costello et al., 2014) have reported

19 indications and outcomes of tracheostomy in this population, but these studies have been small

20 (sample size range: 4-59) and lack external validity because of substantial heterogeneity in

21 institutional practices surrounding postoperative ventilator management and decision-making

22 about tracheostomy. These studies report different patterns of how commonly tracheostomy is

23 used in this population and the timing of its performance. No national analyses have been

24 performed. We used an established, nationally representative administrative database to examine

25 the indications, performance, outcomes, and resource utilization of tracheostomy in children with

26 CHD nationwide. This database provides a novel opportunity to explore broad patterns of

27 tracheostomy in the pediatric CHD population across geography, different practice environments,

28 and different institutional preferences. 
31

32 the years 1997 to 2009 from the Kids' Inpatient Database (KID), part of the Healthcare Cost and

33 Utilization Project (HCUP) of the Agency for Healthcare Research and Quality. KID is the

34 largest publicly available, all-payer database of inpatient pediatric care in the United States. Each 35

\section{Methods}

This study was exempt from institutional review board review because it uses publicly available, deidentified data. Administrative records were extracted from discharge datasets for dataset, released every third year, includes records on a sample of discharges from all community, non-federal, non-rehabilitation hospitals in states that participate in HCUP. Hospitals are identified in KID by type according to classifications established by the National Association of Children's Hospitals and Related Institutions (NACHRI): children's general hospitals, children's specialty hospitals, children's units in a general hospital, or not identified as a children's hospital. KID contains discharge sample weights to facilitate nationally representative estimates based on the sampling design; these weights adjust for growth in participation from 1997, when 2,521 hospitals in 22 participating states submitted records reflective of 6.7 million national discharges, to 2009 , when 4,121 hospitals in 44 states submitted records reflective of 7.4 million national discharges. While KID contains limited data on each inpatient encounter, its size and sampling frame facilitate the analysis of comparatively rare clinical events at a national level. Diagnostic, comorbidity, and procedural information was based on HCUP-supplied international classification of diseases, ninth revision, clinical modification (ICD-9-CM) codes: tracheostomy (Volume 3 procedure codes 31.1-2), congenital heart disease (745.x, 746.x, and 747.1-4), single-ventricle anatomy $(747.7,745.3$, and procedure code 39.21$)$, pulmonary hypertension (416.x), genetic syndromes (758.0-5), vocal cord paralysis/paresis (478.30-34), tracheal or bronchial pathology $(519.1,519.19,748.3)$ and respiratory failure $(518.5 \mathrm{x}, 518.8 \mathrm{x}$, 770.84, 799.1, and V46.1-2). Cardiac surgical procedure codes were used to define whether the tracheostomy was performed during an admission that included a cardiac operation or an 
54 admission that did not. A composite comorbidity point score was calculated based on the van

55 Walraven modification of the Elixhauser comorbidity measure.(Elixhauser et al., 1998)

56 We compared children with CHD who underwent tracheostomy ("CHD group") to

57 children without CHD who underwent tracheostomy ("non-CHD group"). Within the CHD

58 group, we compared admissions of children whose tracheostomy occurred in the same hospital

59 admissions as a cardiac operation ("cardiac surgical group") to those whose tracheostomy

60 occurred without a cardiac operation in the same admission ("nonsurgical group"). Because

61 patients with single-ventricle physiology are a subgroup of particular interest, we also compared

62 children with single-ventricle physiology to those with two-ventricle physiology.

63 Discharge weights were used to create national estimates within the KID sampling frame.

64 Primary outcome measures included inpatient length of stay (variable LOS), timing of the

65 performance of tracheostomy relative to admission and cardiac surgery (calculated from variables

66 PRDAYx), total inpatient hospital charges (variable TOTCHG), and in-hospital mortality

67 (variable DIED). Hospital charges were indexed to inflation by adjusting all values to 2009

68 dollars using the Bureau of Labor Statistics Consumer Price Index subindex specific to inpatient

69 hospital services with a baseline of December 1996 taken as 100.(Bureau of Labor Statistics)

$70 \quad$ Statistical analysis

71 Because the sampling frame of the KID requires the use of advanced techniques

72 (facilitated by PROC SURVEYMEANS in SAS) to estimate variance, continuous variables are

73 presented as mean \pm standard error. Discrete variables are presented as number (percentage).

74 Inter-group comparisons were carried out using the Mann-Whitney-Wilcoxon test for continuous

75 variables and Fisher's exact test or Pearson's chi-squared test for categorical variables, as

76 appropriate. Trends over time were examined by month of hospital admission using a seasonal

77 Mann-Kendall test for trend (a nonparametric test to determine the presence and direction of a 
78 trend over time(Hirsch, Slack \& Smith, 1982) and accounts for seasonal variability, since

79 inpatient pediatric care might involve seasonal fluctuations due to, for instance, patterns of winter 80 illness, surgical scheduling in relation to school calendars, etc). For trend analyses only, records

81 with missing data for the month of admission (8.6\% of all KID records) were excluded; these

82 records were included for all non-trend analyses and descriptive data. A predetermined alpha of

830.05 was used as the threshold of statistical significance. Trend analyses were performed using R

84 (R 3.0.3, The R Foundation for Statistical Computing, Vienna, Austria). All other analyses were 85 performed using SAS (SAS 9.3, SAS Institute, Cary, NC, USA). 
86

87

88

89

90

91

92

93

94

96

97

98

99

100

101

102

103

104

105

106

107

108

109

110

\section{$\underline{\text { Results }}$}

7 Tracheostomy was performed in $n=2,495$ children with $\mathrm{CHD}$, which represents $9.6 \%$ of all tracheostomies performed in children $(n=25,928)$, and $3.5 \%$ of all admissions for children with CHD $(n=355,460)$.

The performance of tracheostomy demonstrated a significantly increasing trend over time among children with and without CHD ( $p<0.0001$ for both, Figure 1). Over the study period, children with CHD accounted for a significantly increasing proportion of all tracheostomies $(p<0.0001$; Figure 2), and tracheostomy admissions accounted for an increasing proportion of admissions among children with CHD ( $<<0.0001$, Figure 3).

Table 1 shows baseline characteristics for the CHD and non-CHD groups. . The CHD group was predominantly $(86 \%)$ neonates or infants, whereas the majority $(63 \%)$ of the non-CHD group was older than age 10. The CHD group had a roughly even balance of boys and girls, whereas the non-CHD group was $64 \%$ male. A greater fraction of the CHD group received Medicaid, received care in urban teaching hospitals, and received care in a recognized children's hospital or unit. Table 2 shows outcomes of tracheostomy admissions in the CHD and non-CHD groups. The CHD group underwent tracheostomy significantly later in their hospitalization, was less likely to be discharged to a skilled nursing or long-term care facility, and had a longer length of stay, greater total hospital charges, and greater in-hospital mortality.

Table 3 shows baseline characteristics for the CHD group, divided into cardiac surgical and nonsurgical subgroups. Children in the cardiac surgical group had were less likely to have tracheal or bronchial pathology and more likely to have respiratory failure as an indication for tracheostomy. Table 4 shows outcomes of tracheostomy admissions in the cardiac surgical and nonsurgical groups. The majority (86\%) of CHD patients in the cardiac surgical group underwent tracheostomy after their cardiac operation, an average of $49.6 \pm 3.1$ days after the cardiac operation and $72.3 \pm 4.5$ days after initial hospital admission. 
111 Table 5 shows outcomes of tracheostomy admissions in children with single-ventricle

112 physiology ( $\mathrm{n}=169,6.8 \%$ of all CHD tracheostomy admissions) compared to children with two-

113 ventricle physiology. Compared to two-ventricle CHD patients, single-ventricle patients had a

114 higher average age ( $1.9 \pm 0.4$ vs $1.1 \pm 0.1$ years $)$, underwent tracheostomy later in their admission

115 (60.0 \pm 5.0 vs $46.2 \pm 1.9$ days $)$, had greater total hospital charges $(\$ 754,764 \pm 47,887$ vs

$116 \$ 593,437 \pm \$ 17,028)$, and much greater in-hospital mortality (35.5\% vs 14.9\%). 


\section{Discussion}

118 The principal finding of this study is that tracheostomy is an increasingly common

119 procedure in children with CHD despite being associated with significantly greater resource

120 utilization and in-hospital mortality.

121 In both the CHD and non-CHD groups, we observed an increasing trend in the proportion

122 of admissions involving tracheostomy. This may reflect a shift in practice towards the belief that

123 earlier tracheostomy improves outcomes for critically ill patients, which has been well-

124 established in adults(Gomes Silva et al., 2012) and has begun to gain acceptance in other

125 pediatric populations, including trauma(Holscher et al., 2014) and burns(Palmieri, Jackson \&

126 Greenhalgh, 2002). However, even beyond this broader overall increase in tracheostomy, we

127 found that children with CHD accounted for an increasing proportion of all tracheostomy

128 admissions. This may reflect increasing acceptance of tracheostomy by congenital heart surgeons

129 as a bridge to recovery in critically ill patients, increasing complexity of cases (with a greater

130 attendant risk of prolonged ICU recovery), or expansion of surgical programs to include children

131 with other comorbid conditions (e.g. pulmonary hypertension) that might previously have been

132 viewed as contraindications to surgical candidacy and that complicate their recovery from

133 congenital heart surgery.

134 The population of children with CHD who undergo tracheostomy differs markedly from

135 that of children without CHD who undergo tracheostomy. The CHD group mostly was composed

136 of a gender-balanced population of neonates and infants at urban, tertiary, children's hospitals,

137 whereas the non-CHD group was comprised mostly of pre-teen and teenage boys. These

138 observations suggest a bimodal pattern of pediatric critical illness, in which CHD is a major

139 contributor in the neonatal and infant period, but a comparatively less common contributor in the

140 school-age and adolescent age group . 
142 important differences between those whose tracheostomy occurred in the same hospital

143 admissions as a cardiac operation and those whose tracheostomy did not. The cardiac surgical

144 group had higher baseline comorbidity scores, were more likely to have care in urban teaching

145 hospitals and in an identified children's hospital or unit. The cardiac surgical group was also less

146 likely to have tracheal or bronchial pathology and more likely to have respiratory failure as an

147 indication for tracheostomy.

148 The cardiac surgical group underwent tracheostomy later in their hospitalization, had a

149 longer length of stay, greater total hospital charges, and greater in-hospital mortality. Within the

150 group that had both a tracheostomy and a cardiac surgical procedure in the same admission, the

151 timing of the two procedures was notable. Most children $(86.4 \%)$ had cardiac surgery prior to

152 their tracheostomy; a minority $(10.5 \%)$ had a tracheostomy prior to cardiac surgery. Performance

153 of tracheostomy on the same day as a cardiac operation was rare $(3.1 \%)$.

154 Children with single-ventricle physiology undergoing tracheostomy were older than those

155 with two-ventricle CHD; the mean age of 1.9 years in the single-ventricle group suggests a

156 predominance of tracheostomies occurring remote from initial palliation, though longitudinal

157 information on sequential surgical procedures is not available. The single-ventricle group was

158 more likely to reflect a tracheostomy performed in a surgical admission, and the longer interval to

159 tracheostomy suggests a prolonged ICU course in an attempt to avoid tracheostomy. This group

160 demonstrated high mortality, with more than 1 in 3 children in the single-ventricle group dying in

161 the same admission in which tracheostomy is performed. We suspect that in this context,

162 tracheostomy is a marker for complex critical illness, but it is also important to note that a causal

163 role may exist, as prolonged positive pressure ventilation may have significant pathophysiologic

164 effects on the single-ventricle circulation.(Shekerdemian et al., 1997) Further investigations 
165 would be needed to determine the benefits and risks of early compared to late tracheostomy in

166 single-ventricle patients with respiratory failure.

167 Our results are consistent with the prior single-institution analyses that have demonstrated

168 significant mortality and long length of stays in pediatric CHD patients who require

169 tracheostomy. Our analysis provides a comprehensive, national depiction of the timing of

170 tracheostomy in cardiac surgical and nonsurgical admissions; prior analyses have provided

171 widely varying information about timing. Our analysis also adds important information about

172 trends over time and across the entire nation, information on resource utilization associated with

173 tracheostomy admissions, and a benchmark to which future in-depth, single-institution studies

174 can compare their practices.

175 We believe it is important to note that KID is a database of admissions, so this analysis

176 does not provide longitudinal data on patients with a tracheostomy through multiple hospital

177 admissions or outpatient events. Any individual child who has multiple hospitalizations may

178 appear in KID multiple times; no mechanism allows for connecting the records from separate

179 admissions, and one must interpret this analysis in light of this feature. For instance, we cannot

180 determine the timing or frequency of readmissions in patients with tracheostomy after the initial

181 admission when the tracheostomy was performed. Administrative data also lack clinical details,

182 including ventilator dependence, tracheostomy decannulation, and tracheostomy-associated

183 surgical complications, so this analysis cannot add information about those dimensions of

184 tracheostomy performance in children with CHD.

185 Several limitations to this study exist as a result of structural features of the KID

186 database. First, all administrative analyses are limited by classification error. However, such

187 error is less likely to occur with respect to procedural codes that are important to reimbursement;

188 hospitals have an incentive to ensure that all performed procedures are coded properly. Similarly,

189 important comorbidity information (e.g. CHD) is more likely to be reliably coded than minor 
coexisting conditions of less significance to the primary problem treated in the admission. These

191 features are likely to mitigate the effects of classification error in our analysis of a major,

192 conspicuous procedure in a population with a major cardiac condition.

193 Classification error is likely to be a particular concern in our analysis of single-ventricle

194 patients, as the diagnosis codes we used to identify single-ventricle physiology are incomplete.

195 Some diagnoses (for instance, atrioventricular canal) include a heterogeneous range of defects

196 that may involve either single-ventricle or two-ventricle physiology, depending on severity. ICD-

1979 codes cannot differentiate the single-ventricle subset of these patients. However, it is most

198 likely that classification error underestimates the single-ventricle population, suggesting that the

199 differences we observed might be even more pronounced if we were able to identify all single-

200 ventricle patients.

201 Second, resource utilization information is available only for the entire hospital

202 admission, which precludes knowledge of the distribution of individual contributors to resource

203 utilization (e.g. medication costs, supplies, procedures). This analysis offers information on

204 resource utilization in admissions of patients undergoing tracheostomy, but it cannot elucidate the

205 resources specifically devoted to tracheostomy itself as compared to other care provided in the

206 same admission.

207 Third, total hospital charges as reported in the NIS represent hospital billing, not actual

208 expenditures or reimbursement. The complex, nonlinear relationships between hospital charges,

209 hospital costs, insurance reimbursement, and patient co-payments complicate the extrapolation of

210 these results to an estimation of the true societal cost of inpatient care in children with a

211 tracheostomy. However, to the degree that the relationship between charges, costs, and other

212 parameters does not change drastically over short periods of time, hospital charges at minimum

213 are useful for analysis of resource utilization trends, allow for aggregation of data at the national

214 level, and give some sense of the magnitude of resource utilization devoted to this population. 
216 from year to year. Discharge weights adjust to produce national estimates for each year, and we

217 also attempted to address this by ensuring that the ICD9 codes used to identify tracheostomy have

218 not changed during the study period.(National Center for Health Statistics and the Centers for

219 Medicare \& \& Services, 2013)

220 Fifth, the trend analyses were limited by a small amount of missing data $(8.6 \%$ of all

221 records did not include the month of admission, only the year). We believe the benefit of greater

222 data granularity outweighed the downsides of this limitation, as use of year only would

223 significantly limit the power of trend analyses and would prohibit any adjustment for seasonal

224 fluctuations.

225 Despite these limitations, this analysis is useful in demonstrating the relative trends in

226 performance of tracheostomy and its resource utilization implications. It captures national

227 practice patterns and outcomes to demonstrate that tracheostomy is an increasingly common

228 intervention in children with CHD, and in children undergoing heart surgery during the same

229 admission, is usually performed significantly later (on average, 49 days) in the admission. It

230 outlines important demographic and clinical differences between children with CHD who

231 undergo tracheostomy and children without CHD who undergo tracheostomy. Future studies must

232 build on these results to further investigate the benefits of early vs late tracheostomy, to

233 determine if the significant resource utilization associated with tracheostomy improves overall

234 resource utilization, recovery, or long-term outcomes. Our subgroup analysis of single-ventricle

235 patients suggests that in particular, focused studies analyzing the benefits of tracheostomy in this

236 subpopulation will be revealing. 
$\underline{\text { References }}$

238 Bureau of Labor Statistics. Consumer Price Index Detailed Reports 1998-2009.

239 Challapudi G, Natarajan G, Aggarwal S. Single-center experience of outcomes of tracheostomy 240 in children with congenital heart disease. Congenital heart disease 8:556-60.

241 Costello JP, Emerson DA, Shu MK, Peer SM, Zurakowski D, Reilly BK, Klugman D, Jonas RA, 242 Nath DS. 2014. Outcomes of Tracheostomy Following Congenital Heart Surgery: A 243 Contemporary Experience. Congenital heart disease.

244 Cotts T, Hirsch J, Thorne M, Gajarski R. 2011. Tracheostomy after pediatric cardiac surgery: 245 246 frequency, indications, and outcomes. The Journal of thoracic and cardiovascular surgery 141:413-8.

247 Elixhauser A, Steiner C, Harris DR, Coffey RM. 1998. Comorbidity measures for use with 248 administrative data. Medical care 36:8-27.

249 Gomes Silva BN, Andriolo RB, Saconato H, Atallah AN, Valente O. 2012. Early versus late 250 tracheostomy for critically ill patients. The Cochrane database of systematic reviews $251 \quad 3: C D 007271$.

Hirsch RM, Slack JR, Smith RA. 1982. Techniques of trend analysis for monthly water quality

254

255

256

257

258

259

260

261

262

263

264 265

266 267 data. Water Resources Research 18:107-121.

Holscher CM, Stewart CL, Peltz ED, Burlew CC, Moulton SL, Haenel JB, Bensard DD. 2014. Early tracheostomy improves outcomes in severely injured children and adolescents. Journal of pediatric surgery 49:590-2.

Hoskote A, Cohen G, Goldman A, Shekerdemian L. 2005. Tracheostomy in infants and children after cardiothoracic surgery: indications, associated risk factors, and timing. The Journal of thoracic and cardiovascular surgery 130:1086-93.

Van der Linde D, Konings EEM, Slager MA, Witsenburg M, Helbing WA, Takkenberg JJM, Roos-Hesselink JW. 2011. Birth prevalence of congenital heart disease worldwide: a systematic review and meta-analysis. Journal of the American College of Cardiology $58: 2241-7$.

LoTempio MM, Shapiro NL. Tracheotomy tube placement in children following cardiothoracic surgery: indications and outcomes. American journal of otolaryngology 23:337-40.

National Center for Health Statistics and the Centers for Medicare \&, Services. 2013. Conversion Table of New ICD-9-CM Codes. 
268 Nieminen HP, Jokinen E V, Sairanen HI. 2001. Late results of pediatric cardiac surgery in 269 Finland: a population-based study with 96\% follow-up. Circulation 104:570-5.

270 Palmieri TL, Jackson W, Greenhalgh DG. 2002. Benefits of early tracheostomy in severely 271 burned children. Critical care medicine 30:922-4.

272 Rossi AF, Fishberger S, Hannan RL, Nieves JA, Bolivar J, Dobrolet N, Burke RP. 2009.

273 Frequency and indications for tracheostomy and gastrostomy after congenital heart surgery.

$274 \quad$ Pediatric cardiology 30:225-31.

275 Shekerdemian LS, Bush A, Shore DF, Lincoln C, Redington AN. 1997. Cardiopulmonary

276 interactions after Fontan operations: augmentation of cardiac output using negative pressure 277 ventilation. Circulation 96:3934-42.

278 Székely A, Sápi E, Király L, Szatmári A, Dinya E. 2006. Intraoperative and postoperative risk 279 factors for prolonged mechanical ventilation after pediatric cardiac surgery. Paediatric 280 anaesthesia 16:1166-75. 


\section{Figure 1}

National estimates of total admissions including the performance of tracheostomy by month

Children with CHD (blue bars; increasing trend, $\mathrm{p}<0.0001$ ); children without CHD (red bars; increasing trend, $p<0.0001)$.

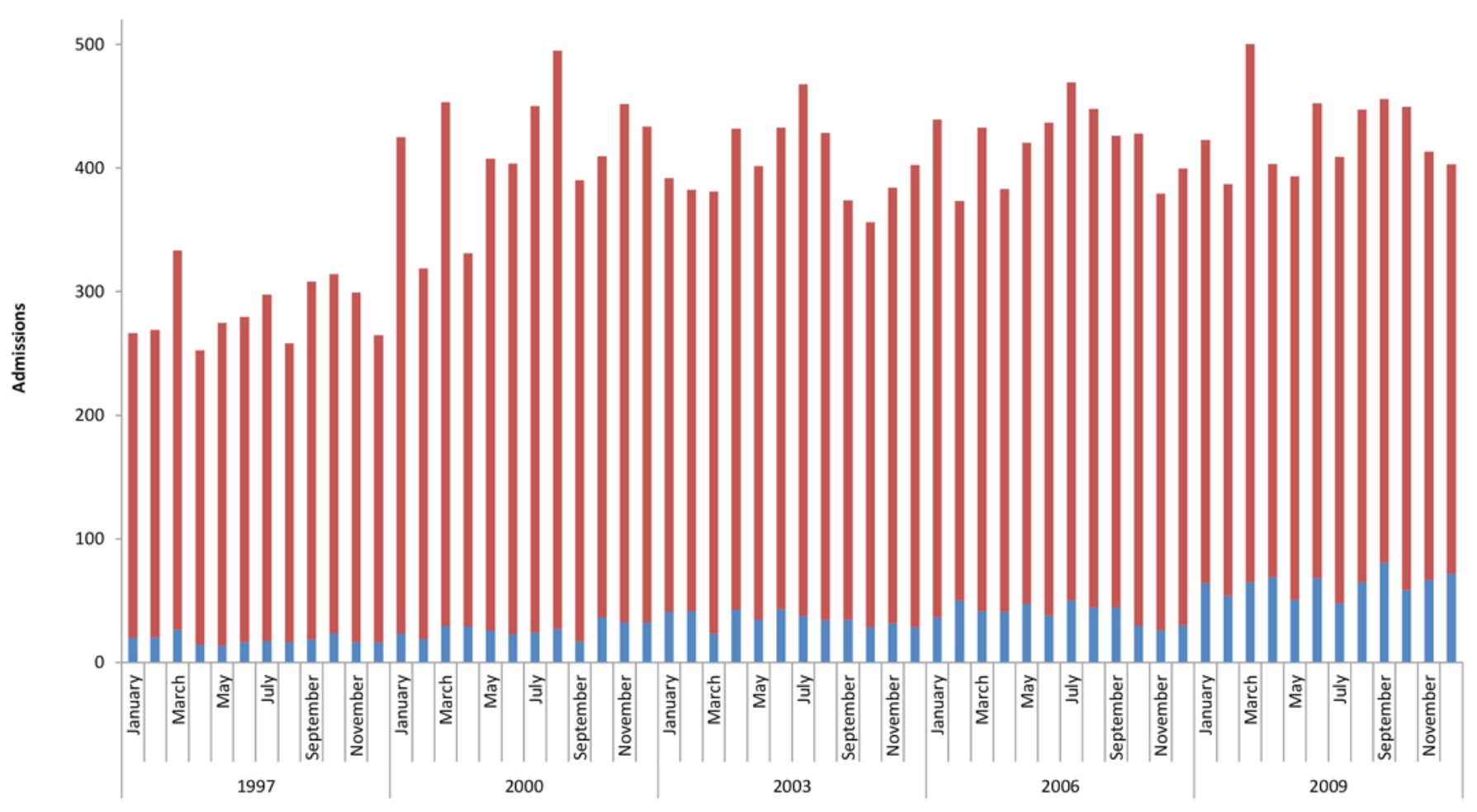




\section{Figure 2}

Proportion of all pediatric admissions with performance of a tracheostomy accounted for by children with CHD, by month.

Increasing trend, $p<0.0001$.

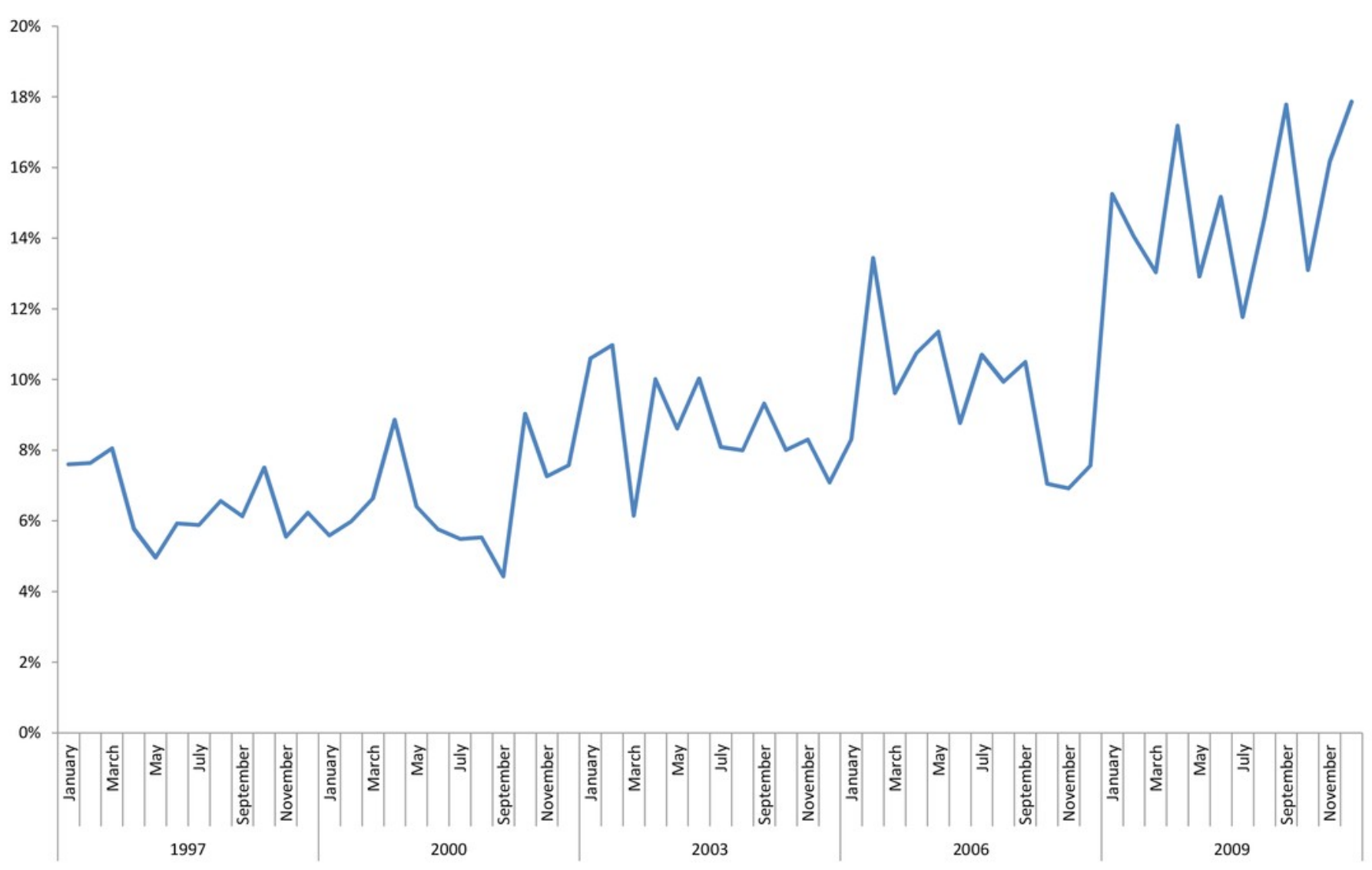




\section{Figure 3}

Percentage of all admissions of children with CHD that involve performance of a tracheostomy.

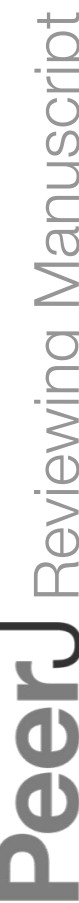

Increasing trend, $p<0.0001$.

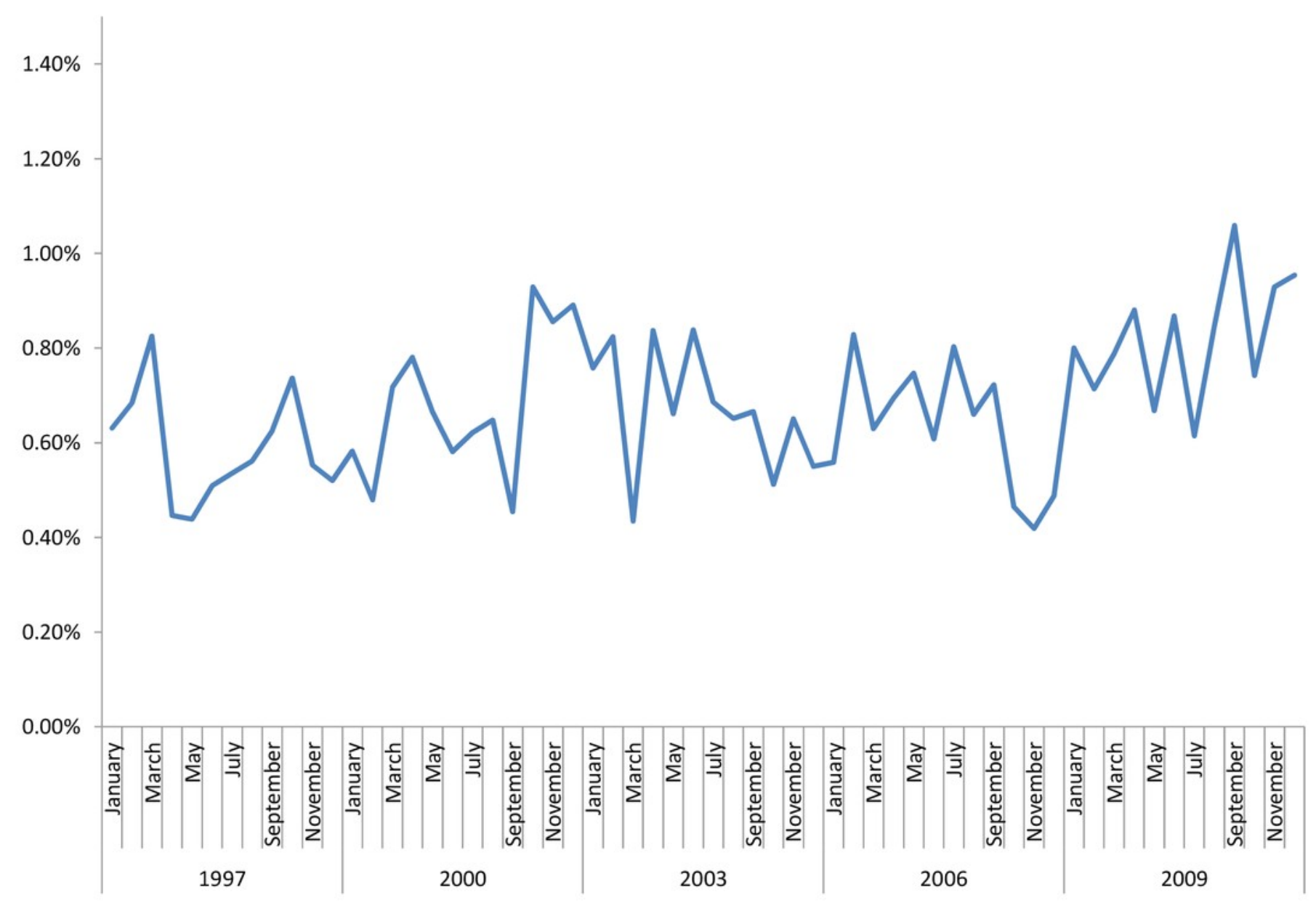




\section{Table 1 (on next page)}

Characteristics of children with and without congenital heart disease undergoing tracheostomy. 
Table 1: $\quad$ Characteristics of children with and without congenital heart disease undergoing tracheostomy.

\begin{tabular}{|c|c|c|c|c|c|}
\hline & & $\begin{array}{l}\text { HD } \\
2495\end{array}$ & & $\begin{array}{l}\text { CHD } \\
23433\end{array}$ & $\mathrm{p}$ \\
\hline & $\mathrm{n}$ & $\%$ & $\mathrm{n}$ & $\%$ & \\
\hline Age (years) & 1.2 & \pm 0.1 & 11.2 & \pm 0.2 & $\begin{array}{c}<0.00 \\
01\end{array}$ \\
\hline Age category & & & & & $\begin{array}{c}<0.00 \\
01\end{array}$ \\
\hline Birth admission & 513 & $(20.6 \%)$ & 1453 & $(6.2 \%)$ & \\
\hline$<1 y r$, readmission since birth & 1631 & $(65.4 \%)$ & 4462 & $(19.0 \%)$ & \\
\hline age $1-4$ & 190 & $(7.6 \%)$ & 1771 & $(7.6 \%)$ & \\
\hline age $5-9$ & 42 & $(1.7 \%)$ & 940 & $(4.0 \%)$ & \\
\hline age $>=10$ & 119 & $(4.8 \%)$ & 14807 & $(63.2 \%)$ & \\
\hline$\underline{\text { Sex }}$ & & & & & $\begin{array}{c}<0.00 \\
01\end{array}$ \\
\hline Male & 1284 & $(51.5 \%)$ & 15083 & $(64.4 \%)$ & \\
\hline Female & 1211 & $(48.5 \%)$ & 8350 & $(35.6 \%)$ & \\
\hline$\underline{\text { Race }}$ & & & & & $<0.00$ \\
\hline White & 913 & $(36.6 \%)$ & 9682 & $(41.3 \%)$ & \\
\hline Black & 391 & $(15.7 \%)$ & 3803 & $(16.2 \%)$ & \\
\hline Hispanic & 465 & $(18.6 \%)$ & 3311 & $(14.1 \%)$ & \\
\hline Asian & 51 & $(2.0 \%)$ & 475 & $(2.0 \%)$ & \\
\hline Other/Missing & 675 & $(27.0 \%)$ & 6162 & $(26.3 \%)$ & \\
\hline van Walraven score & 4.0 & \pm 0.2 & 4.1 & \pm 0.1 & 0.2958 \\
\hline Genetic syndrome & 254 & $(10.2 \%)$ & 353 & $(1.5 \%)$ & $<0.00$ \\
\hline Pulmonary hypertension & 241 & $(9.7 \%)$ & 405 & $(1.7 \%)$ & $<0.00$ \\
\hline Vocal cord paralysis/paresis & 150 & $(6.0 \%)$ & 864 & $(3.7 \%)$ & $<0.00$ \\
\hline Tracheal/bronchial pathology & 706 & $(28.3 \%)$ & 2428 & $(10.4 \%)$ & $<0.00$ \\
\hline Respiratory failure & 1383 & $(55.4 \%)$ & 1374 & $(58.6 \%)$ & 0.008 \\
\hline Payer & & & & & $\begin{array}{c}<0.00 \\
01\end{array}$ \\
\hline Medicare & ** & ** & 84 & $(0.4 \%)$ & \\
\hline Medicaid & 1390 & $(55.7 \%)$ & 9936 & $(42.4 \%)$ & \\
\hline Private insurance & 947 & $(38.0 \%)$ & 10859 & $(46.3 \%)$ & \\
\hline Self-pay/other & 154 & $(6.2 \%)$ & 2554 & $(10.9 \%)$ & \\
\hline Hospital Setting & & & & & $\begin{array}{c}<0.00 \\
01\end{array}$ \\
\hline Rural & 16 & $(0.7 \%)$ & 415 & $(1.8 \%)$ & \\
\hline Urban, nonteaching & 250 & $(10.0 \%)$ & 3501 & $(14.9 \%)$ & \\
\hline Urban, teaching & 2229 & $(89.3 \%)$ & 19517 & $(83.3 \%)$ & \\
\hline$\underline{\text { Hospital Type* }}$ & & & & & $\begin{array}{c}<0.00 \\
01\end{array}$ \\
\hline
\end{tabular}




$\begin{array}{lccrc}\text { Children's general hospital } & 759 & (30.4 \%) & 3393 & (14.5 \%) \\ \begin{array}{l}\text { Children's specialty hospital } \\ \text { Children's unit in a general }\end{array} & * * & * * & 42 & (0.2 \%) \\ \begin{array}{c}\text { hospital } \\ \text { Not identified as a children's }\end{array} & 1103 & (44.2 \%) & 9085 & (38.8 \%) \\ \text { hospital } & 633 & (25.4 \%) & 10913 & (46.6 \%)\end{array}$

**number not reported in keeping with KID privacy rules for cells with $\mathrm{n}<10$. True values used to calculate $\mathrm{p}$ values.

Values are number (percentage) or mean \pm standard error, as appropriate. 


\section{Table 2 (on next page)}

Outcomes of tracheostomy in children with and without congenital heart disease. 
Table 2: $\quad$ Outcomes of tracheostomy in children with and without congenital heart disease.

\begin{tabular}{|c|c|c|c|c|c|}
\hline & \multicolumn{2}{|c|}{$\begin{array}{c}\text { CHD } \\
n=2495\end{array}$} & \multicolumn{2}{|c|}{$\begin{array}{l}\text { No CHD } \\
n=23433\end{array}$} & \multirow[t]{2}{*}{$p$} \\
\hline & $\mathrm{n}$ & $\%$ & $\mathrm{n}$ & $\%$ & \\
\hline $\begin{array}{l}\text { Days from admission to } \\
\text { tracheostomy }\end{array}$ & 47.0 & \pm 1.8 & 18.4 & \pm 0.5 & $\begin{array}{c}<0.00 \\
01\end{array}$ \\
\hline Length of stay (days) & 98.6 & \pm 2.5 & 47.4 & \pm 0.9 & $\begin{array}{c}<0.00 \\
01\end{array}$ \\
\hline Total hospital charges & $\begin{array}{r}\$ 603,6 \\
51\end{array}$ & $\stackrel{ \pm}{ \pm 16,479}$ & $\begin{array}{r}\$ 368,9 \\
56\end{array}$ & $\$ \frac{ \pm}{\$ 7,344}$ & $\begin{array}{c}<0.00 \\
01\end{array}$ \\
\hline $\begin{array}{l}\text { Discharge disposition (of alive } \\
\text { discharges) }\end{array}$ & & & & & $\begin{array}{c}<0.00 \\
01\end{array}$ \\
\hline Home, routine & 862 & $(41.3 \%)$ & 7673 & $(35.1 \%)$ & \\
\hline Home with home health & 581 & $(27.8 \%)$ & 3571 & $(16.3 \%)$ & \\
\hline $\begin{array}{l}\text { Nursing facility/subacute/long- } \\
\text { term care }\end{array}$ & 645 & $(30.9 \%)$ & 10636 & $(48.6 \%)$ & \\
\hline Mortality & 407 & $(16.3 \%)$ & 1553 & $(6.6 \%)$ & $\begin{array}{c}<0.00 \\
01\end{array}$ \\
\hline
\end{tabular}

Values are number (percentage) or mean \pm standard error, as appropriate. 


\section{Table 3 (on next page)}

Characteristics of children with congenital heart disease undergoing tracheostomy in admissions involving cardiac surgery or nonsurgical admissions. 
Table 3: Characteristics of children with congenital heart disease undergoing tracheostomy in admissions involving cardiac surgery or nonsurgical admissions.

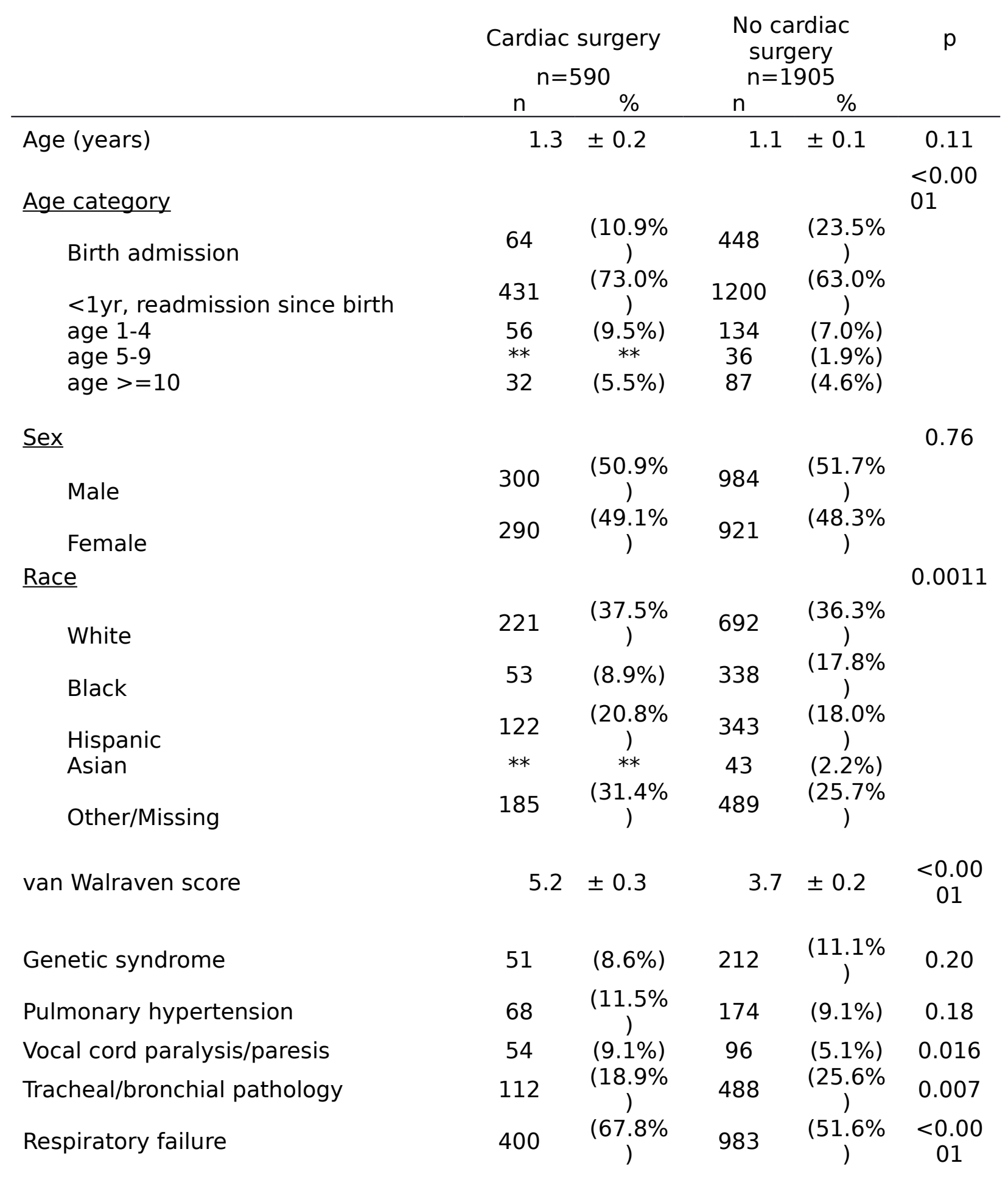




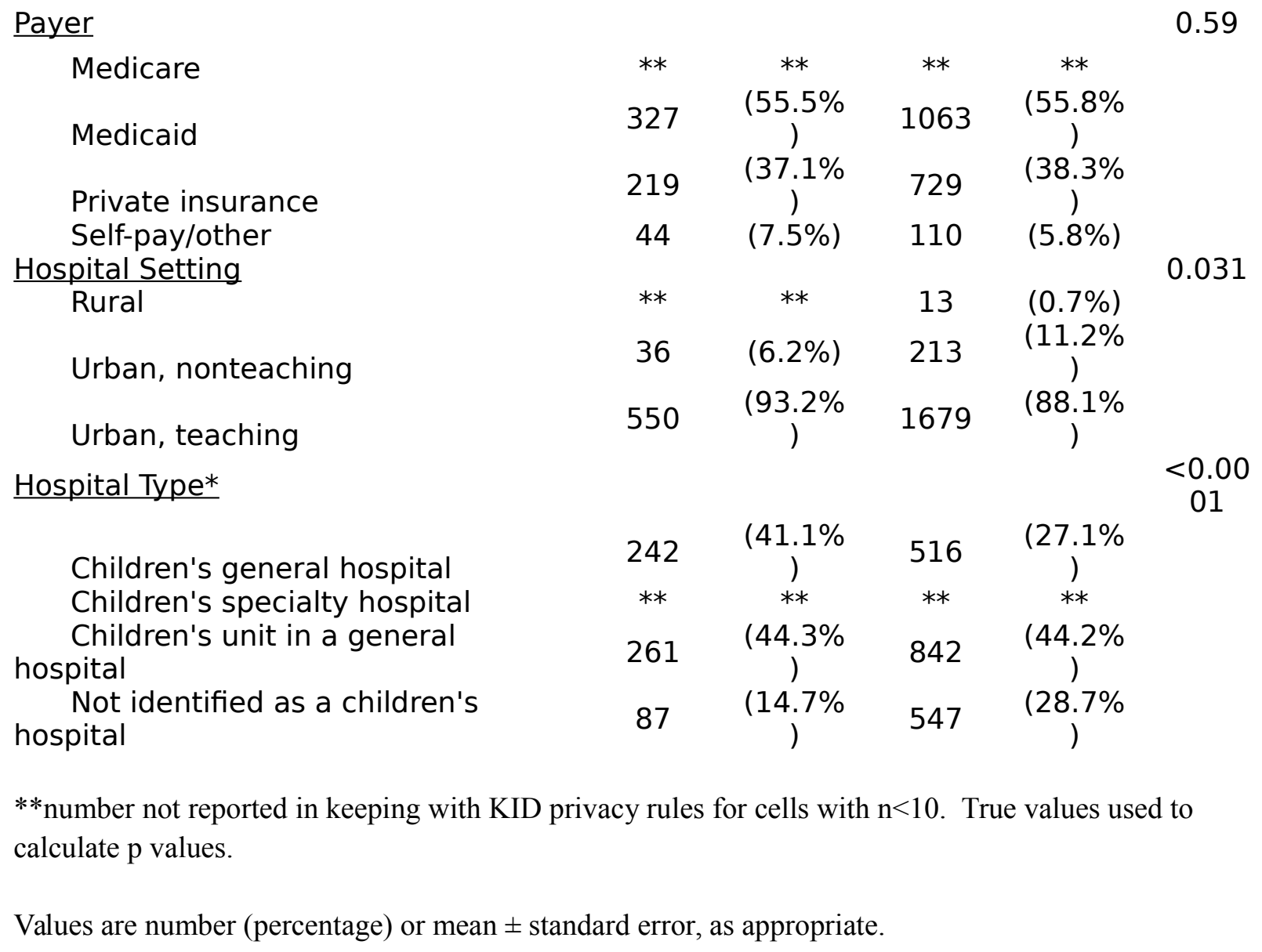




\section{Table 4(on next page)}

Outcomes of tracheostomy in children with congenital heart disease during cardiac surgical or nonsurgical admissions. 
Table 4: $\quad$ Outcomes of tracheostomy in children with congenital heart disease during cardiac surgical or nonsurgical admissions.

\begin{tabular}{|c|c|c|c|c|c|}
\hline & \multicolumn{2}{|c|}{$\begin{array}{l}\text { Cardiac surgery } \\
\qquad \mathrm{n}=590\end{array}$} & \multicolumn{2}{|c|}{$\begin{array}{c}\text { No cardiac } \\
\text { surgery } \\
n=1905\end{array}$} & \multirow[t]{2}{*}{$\mathrm{p}$} \\
\hline & $\mathrm{n}$ & $\%$ & $\mathrm{n}$ & $\%$ & \\
\hline Days from admission to cardiac surgery & 28.5 & \pm 4.0 & & & \\
\hline Days from admission to tracheostomy & 64.8 & \pm 3.7 & 42.2 & \pm 1.9 & $\begin{array}{c}<0.00 \\
01\end{array}$ \\
\hline \multicolumn{6}{|l|}{$\begin{array}{l}\text { Timing of tracheostomy relative to } \\
\text { cardiac surgery }\end{array}$} \\
\hline Same day & 18 & $(3.1 \%)$ & & & \\
\hline Tracheostomy before cardiac surgery & 62 & $(10.5 \%)$ & & & \\
\hline $\begin{array}{l}\text { Days from admission to } \\
\text { tracheostomy }\end{array}$ & 44.3 & \pm 4.1 & & & \\
\hline $\begin{array}{l}\text { Days from tracheostomy to cardiac } \\
\text { surgery }\end{array}$ & 46.6 & \pm 9.5 & & & \\
\hline $\begin{array}{l}\text { Days from admission to cardiac } \\
\text { surgery }\end{array}$ & 74.1 & \pm 14.5 & & & \\
\hline Tracheostomy after cardiac surgery & 510 & $(86.4 \%)$ & & & \\
\hline $\begin{array}{l}\text { Days from admission to cardiac } \\
\text { surgery }\end{array}$ & 22.7 & \pm 4.1 & & & \\
\hline $\begin{array}{l}\text { Days from cardiac surgery to } \\
\text { tracheostomy }\end{array}$ & 49.6 & \pm 3.1 & & & \\
\hline $\begin{array}{l}\text { Days from admission to } \\
\text { tracheostomy }\end{array}$ & 72.3 & \pm 4.5 & & & \\
\hline Length of stay (days) & 119.2 & \pm 5.2 & 92.3 & \pm 2.5 & $\begin{array}{c}<0.00 \\
01\end{array}$ \\
\hline Total hospital charges & $\begin{array}{r}\$ 844,9 \\
14\end{array}$ & $\stackrel{ \pm}{ \pm 32,124}$ & $\begin{array}{r}\$ 548,5 \\
15\end{array}$ & $\begin{array}{c} \pm \\
\$ 17,66 \\
0\end{array}$ & $\begin{array}{c}<0.00 \\
01\end{array}$ \\
\hline $\begin{array}{l}\text { Discharge disposition (of alive } \\
\text { discharges) }\end{array}$ & & & & & 0.20 \\
\hline Home, routine & 255 & $(43.2 \%)$ & 776 & $(40.8 \%)$ & \\
\hline Home with home health & 139 & $(23.5 \%)$ & 553 & $(29.1 \%)$ & \\
\hline $\begin{array}{l}\text { Nursing facility/subacute/long-term } \\
\text { care }\end{array}$ & 196 & $(33.2 \%)$ & 576 & $(30.3 \%)$ & \\
\hline Mortality & 133 & $(22.5 \%)$ & 274 & $(14.4 \%)$ & $\begin{array}{c}<0.00 \\
01\end{array}$ \\
\hline
\end{tabular}


Values are number (percentage) or mean \pm standard error, as appropriate. 


\section{Table 5(on next page)}

Outcomes of tracheostomy in children with congenital heart disease and single-ventricle physiology compared to children with congenital heart disease and two-ventricle physiology. 
Table 5: Outcomes of tracheostomy in children with congenital heart disease and singleventricle physiology compared to children with congenital heart disease and twoventricle physiology.

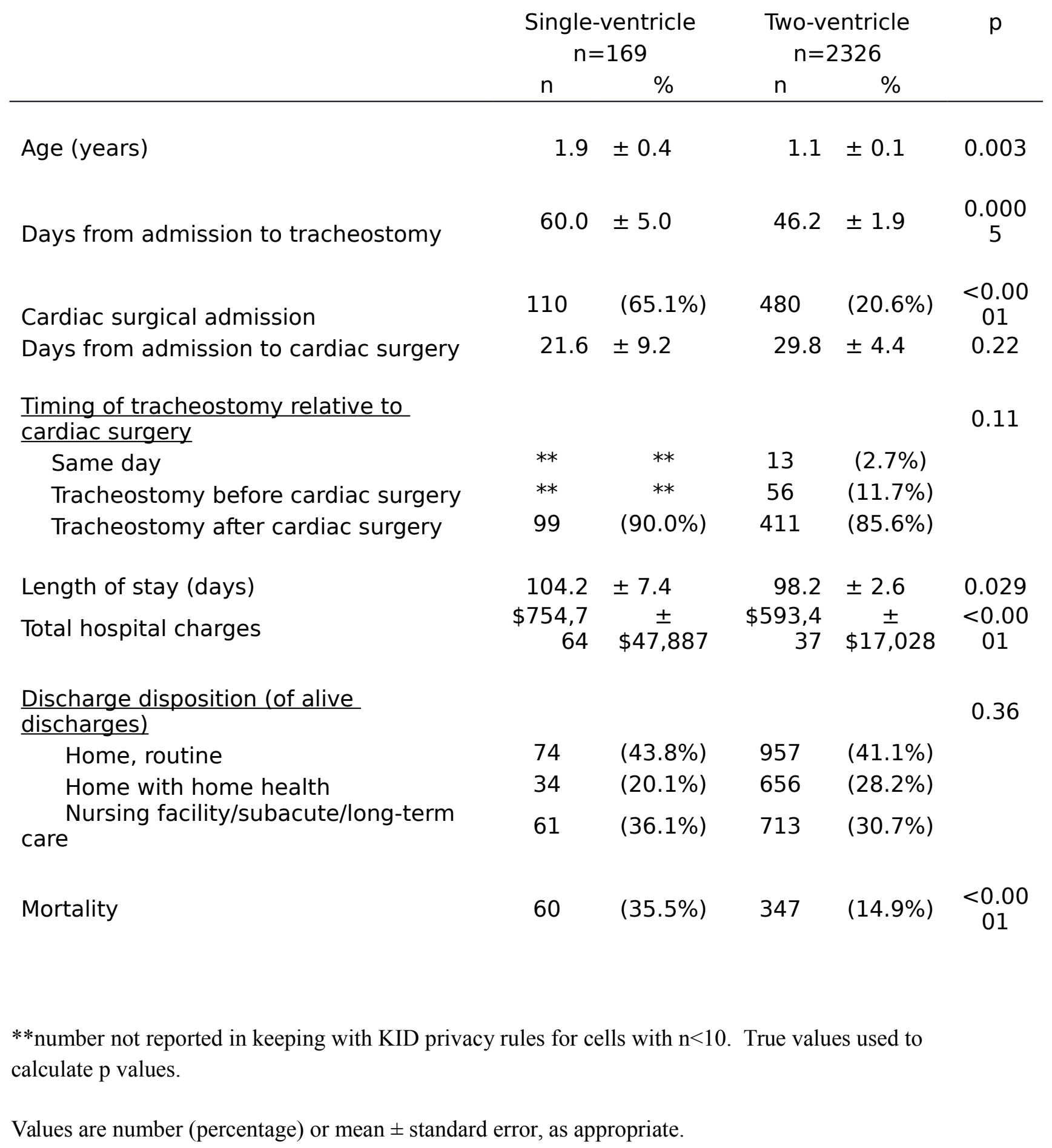




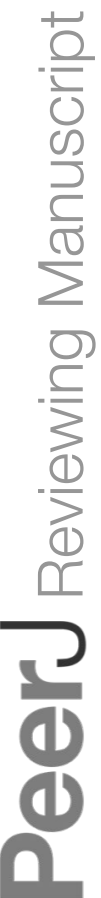

PeerJ reviewing PDF | (v2014:06:2283:3:0:NEW 18 Aug 2014) 